\title{
Global analysis of response and recovery of benthic biota to fishing
}

\author{
M. J. Kaiser ${ }^{1, *}$, K. R. Clarke ${ }^{2}$, H. Hinz ${ }^{1}$, M. C. V. Austen ${ }^{2}$, P. J. Somerfield ${ }^{2}$, I. Karakassis ${ }^{3}$ \\ ${ }^{1}$ School of Ocean Sciences, University of Wales-Bangor, Menai Bridge, Anglesey LL59 5AB, UK \\ ${ }^{2}$ Plymouth Marine Laboratory, Prospect Place, West Hoe, Plymouth PL1 3DH, UK \\ ${ }^{3}$ Institute of Marine Biology of Crete, PO Box 2214, Heraklion 71003, Crete, Greece
}

\begin{abstract}
Towed bottom-fishing gears are thought to constitute one of the largest global anthropogenic sources of disturbance to the seabed and its biota. The current drive towards an ecosystem approach in fisheries management requires a consideration of the implications of habitat deterioration and an understanding of the potential for restoration. We undertook a meta-analysis of 101 different fishing impact manipulations. The direct effects of different types of fishing gear were strongly habitat-specific. The most severe impact occurred in biogenic habitats in response to scallop-dredging. Analysis of the response of different feeding guilds to disturbance from fishing revealed that both deposit- and suspension-feeders were consistently vulnerable to scallop dredging across gravel, sand and mud habitats, while the response of these groups to beam-trawling was highly dependent upon habitat type. The biota of soft-sediment habitats, in particular muddy sands, were surprisingly vulnerable, with predicted recovery times measured in years. Slow-growing large-biomass biota such as sponges and soft corals took much longer to recover (up to 8 yr) than biota with shorter life-spans such as polychaetes $(<1 \mathrm{yr})$. The results give a possible basis for predicting the outcome of the use of different fishing gears in a variety of habitats with potential utility in a management context.
\end{abstract}

KEY WORDS: Fishing impacts · Towed gears · Benthic habitats $\cdot$ Feeding guilds $\cdot$ Meta-analysis $\cdot$ Recovery time

Resale or republication not permitted without written consent of the publisher

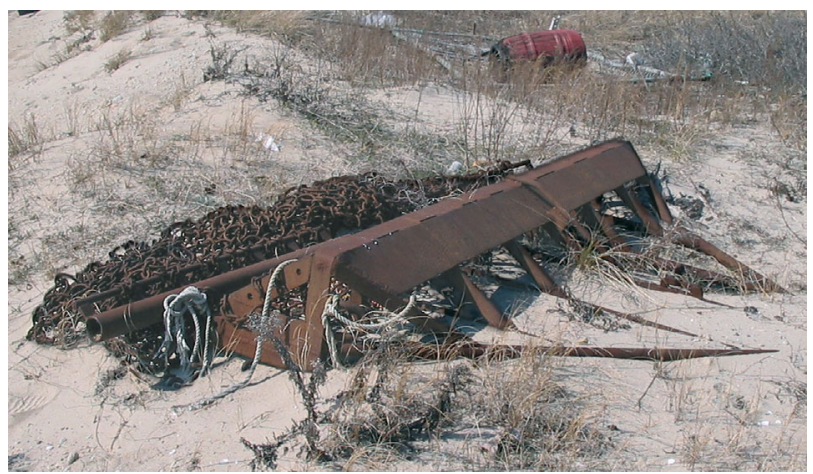

A meta-analysis of 101 experimental fishing impact studies identified the types of fishing gear that have the greatest impact on the seabed and on the groups of organisms that are most vulnerable to fishing activities. Scallop dredges (photo) consistently had the most severe ecological effects. This study quantifies the sustainability of fisheries according to the resilience of the habitat in question.

Photo: Michel Kaiser

\section{INTRODUCTION}

Towed bottom-fishing gears are used worldwide to extract marine resources. In most cases, these gears are used in direct physical contact with the seabed to ensure adequate capture rates of target species that live close to, on or within the seabed (Jennings \& 
Kaiser 1998). In addition to the associated by-catches of non-target species, the fishing process causes varying levels of disturbance to the seabed that alters seabed complexity, removes, damages or kills biota, and reduces benthic production, and thereby can lead to substantial changes in benthic community structure and habitat (Dayton et al. 1995, Engel et al. 1998, Auster \& Langton 1999, Lindegarth et al. 2000, McConnaughy et al. 2000, Kaiser et al. 2002). Individual empirical studies designed to test the effects of particular fishing activities on the benthos have yielded inconsistent findings. The latter is the product of the wide variation in the design and method of deployment of fishing gears, habitat and other environmental factors specific to each case-study (Dayton et al. 1995, Jennings \& Kaiser 1998, Auster \& Langton 1999, Collie et al. 2000, Jennings et al. 2001a,b, Kaiser et al. 2002). Review articles on this topic are numerous (e.g. Dayton et al. 1995, Jennings \& Kaiser 1998, Auster \& Langton 1999, Kaiser et al. 2002) and while these serve to summarise the available data and provide intuitive insights into ecological responses, none have been able to provide unequivocal advice based on a quantitative analysis of global responses of benthic fauna and habitats to fishing disturbance. Reviews of the available literature are open to interpretation and distortion by different user groups (fishers, scientists, conservationists) and hence their utility to marine environmental policy makers is limited at present. The lack of a quantitative and unified integration of the disparate empirical studies undertaken to date is of even more concern given the new drive towards ecosystem approaches to fisheries management that are supposed to integrate the wider ecological effects of fishing (Jackson et al. 2001, Pikitch et al. 2004).

In a previous synthesis of the global trends in the response of benthic biota and habitats to fishing disturbance, a collection of fishing-impact studies was investigated to ascertain patterns in the responses of biota to fishing disturbance, and how these might vary with habitat, depth, disturbance type and among different taxa (Collie et al. 2000). Although this study yielded useful insights, the paucity of studies of sufficient quality restricted the level to which the data could be explored in a rigorous manner, especially with respect to the time taken for recovery to occur. Gaps in the data hindered meaningful interpretation of fishing effects for some of the most vulnerable habitat types. The increase in published studies of fishing impacts has almost doubled the pool of data amassed for the present study to 2474 data points, although considered here are only the experimental studies in which specific taxa ( $n=1759$ values) or summary statistics (total species or number of individuals; $\mathrm{n}=107$ values) have been related to control conditions. This has provided sufficient data to enable the examination of interactions between different factors such as fishing geartype and habitat. These interactions are most pressing in terms of global policy and management, given the desire of managers to understand which fishing activities are most deleterious in certain categories of habitat, and the need to understand the possible timescales of recovery following impact.

Meta-analysis is the quantitative summary of multiple, independent studies to detect general relationships (Gurevitch \& Hedges 1999) permitting ecological questions to be examined on a much larger scale than would otherwise be possible. The relationships and parameters of interest are estimated via data from numerous sources, usually of differing variances, with the resulting combined estimates having validity if each study generates an unbiased outcome (however imprecise). While meta-analysis is a proven approach for the examination of wide-scale responses of ecological variables, it is open to abuse by a tendency to sample only those studies that report significant results or results that favour a particular outcome. Additionally, the data in the source papers may be biased towards results that are significant, with a disproportionate non-reporting of non-significant effects, i.e. publication bias (Gates 2002, Murtaugh 2002). For the current analysis, we attempted to include all those studies available to us at the time this work was carried out, both from peer-reviewed and grey literature, although the latter occurred relatively infrequently or has subsequently been published in the primary literature. It is arguable that the bias to publish only studies that report significant effects of fishing is less likely than in other research areas, as a non-significant effect of fishing activity has important political implications and hence is of equal scientific importance. We recognise, however, that any meta-analysis will always suffer from some degree of publication bias, and should be interpreted with appropriate caution. What such analyses lose in specificity and consistency of experimental format, they gain in the generality of findings and the scale of observations that can be assembled, and this study is no exception.

\section{METHODS}

Available data. We found 101 different experimental manipulations or observations of the effects of fishing disturbance on benthic fauna and communities, extracted from 55 separate publications (Appendix 1, available at www.int-res.com/articles/suppl/m311p001_ app.pdf). This does not include comparative studies that studied areas of the seabed subjected to different levels of fishing activity, as these have an unknown 
level of fishing frequency and intensity and it was not possible to estimate the time taken for recovery (e.g. Kaiser et al. 2000a,b). We have assembled the majority of studies relevant for a large-scale synthesis, but there will undoubtedly be some that we have unintentionally missed. Some studies have been subdivided as they incorporated distinctly different experimental manipulations conducted under different environmental conditions, for example comparable manipulations of a fishing disturbance but in 2 distinctly different habitats.

Experimental studies were classified with respect to a range of variables that might affect the degree of trawling impact, including fishing gear type, disturbance regime, water depth $(\mathrm{m})$, the minimum dimension of the reported scale of disturbance (e.g. the width of a trawl), habitat type (mud, muddy sand, sand, gravel and biogenic habitat), and taxonomic grouping (e.g. by phylum) (see Collie et al. 2000 for details). The definition of these broad habitat categories is not precise, as many authors did not give particle-size ranges but just made qualitative statements regarding sediment; however, we take mud, muddy sand and sand to fall within those definitions used by sedimentologists, while gravel is defined as coarse sediments that include a high proportion of gravel and/or broken shell debris, and biogenic habitats as those constructed or composed primarily of living biota (Holme \& MacIntyre 1984). Some studies included the effects of fishing disturbance on univariate summary data, i.e. the total numbers of individuals and species richness, which were extracted together with the effects at different phylogenetic levels (when reported).

Although a fair number of potentially controlling variables were extracted from the available studies, many of these proved to be strongly inter-correlated (e.g. minimum dimension of disturbance and fishing gear type). In our opinion, the most relevant interaction is that between different fishing gear types and habitat (which is strongly correlated with depth), with respect to current fisheries management and habitat conservation needs, and we take these to be the paramount driving variables whose interaction is the focus of the present study.

Response measure. Responses for specific taxa were treated as independent observations in order to examine the effects of the potential explanatory variables on population responses irrespective of taxon. The magnitude of the response of each variable to the fishing treatment was calculated from the following equation, using the mean values for fished and unfished plots in any given study:

$$
\% \text { difference } X=\left[\left(A_{\mathrm{f}}-A_{\mathrm{c}}\right) / A_{\mathrm{c}}\right] \times 100
$$

where $A_{\mathrm{f}}$ is abundance in fished plots and $A_{\mathrm{c}}$ is abundance in unfished control plots. For cases in which the study involved a 'before fishing-after fishing' comparison for the same plot(s), rather than a 'treatmentcontrol' design, these data were used to calculate percentage difference by comparison of the prefishing treatment $\left(A_{\mathrm{c}}\right)$ with the post-fishing condition $\left(A_{\mathrm{f}}\right)$.

The percentage difference measure of the size effect contrasts with that used in most meta-analyses where normalisation is done with respect to some measure of sample variability. Sample variance was often not reported in the studies that we examined, and because much of our response data are for a variety of different taxa, with very different initial densities, percent change from initial densities provides a more meaningful common scale of measurement. In adopting this approach, however, all studies (and all species within each study) are given equal weighting. Clearly this would not be the most statistically efficient analysis (in the sense of reducing the precision of the estimate of means) if quantitative estimates of reliability for different species and variation in the quality of experimental design among the population of studies were known. However, it is not bias that is generally introduced by suboptimal weighting of component information, merely imprecision of resulting estimates, so for the purposes of this comparative analysis it is a desirable expedient to give each component taxon within all our studies equal weight: it is difficult to imagine an alternative strategy without severely diminishing the amount of usable information.

Recovery data. While the majority of studies reported initial impacts of fishing, we were particularly interested in those studies that reported changes in response during a post-fishing recovery period. We analysed these data using 2 approaches. Initially, we categorised data into first 2 and then 4 discrete postfishing time periods. While this resulted in the loss of some of the fine-scale variation in the response time to post-fishing, this 'discretised' approach enabled us to increase the balance and thus robustness of the data set for subsequent analysis of variance. Once this global-level test had been carried out, to indicate the probable presence of time effects of post-fishing disturbance, subsets of the data (e.g. specific gears in specific habitats) were examined to ascertain the rate of post-fishing recovery, with time reinstated as a continuous variable. A piecemeal analysis of this type is inevitable in such meta-analyses: there is no control over the quantity of data representing each of the main fishing gear and habitat combinations, or the recovery time-scales that are monitored. In formal ANOVA terms, designs are hopelessly compromised in terms of balance of replication, in fact very many of the 100 cells in a 3-way crossed layout of gear 'habitat' recovery period are entirely devoid of data, even with a total of 1759 data points in the dataset. 


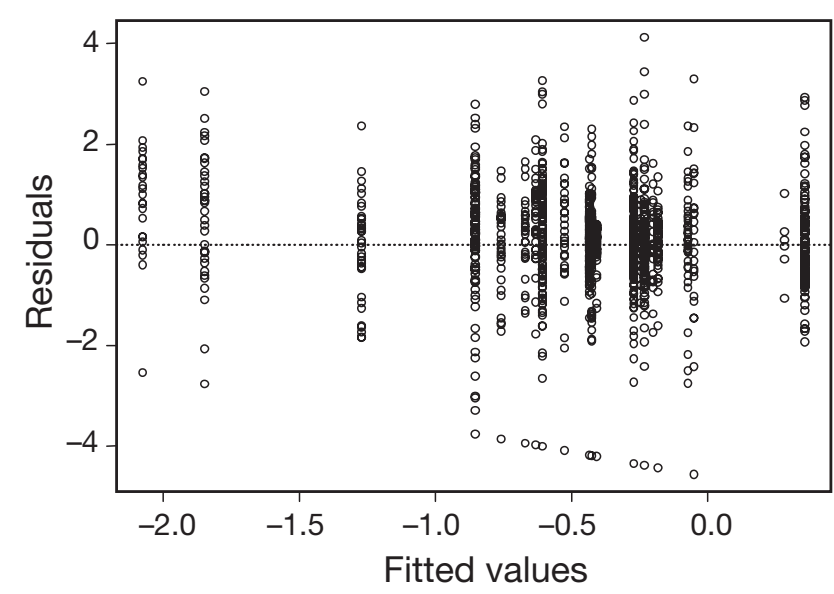

Fig. 1. Typical plot of residuals resulting from transformation $Y=\log _{\mathrm{e}}(1+[\%$ change from control] $/ 101)$ of the percentagechange data. Transformation approximately normalises data and stabilises variance

Statistical analyses. Transformation: The use of percentage change for all response variables means that the most extreme cases of a negative impact are constrained to $-100 \%$ difference compared with the initial or control conditions. Conversely, positive increases in the response variables are potentially limitless i.e. $\gg 100 \%$ increase. The consequence is that the percentage difference variable $(X)$ tends to have a right-skewed distribution; hence, prior to any analyses, the response variable was transformed in the following manner:

$$
Y=\log _{\mathrm{e}}(1+[X / 101])
$$

This transformation succeeds in approximately normalising the error distribution and stabilising its variance (Fig. 1). The transformed percentage difference statistic $(Y)$ was calculated both for bulk community properties, such as total species richness $(S)$ or total counts $(I)$ (or biomass $(B)$ ), and for the abundance (or biomass) of individual taxa, the latter being recorded at the genus level where possible. Bulk properties, such as $S$ and $I$, were analysed separately from counts of individual taxa. Thus the response of each variable to the fishing treatment is expressed on a log-scale, where values range from -4.6 (complete removal), through -0.7 (50\% reduction) and 0 (no response) to +0.7 (2-fold increase) and +4.6 (a 100-fold increase).

Hypotheses and ANOVA tests: The first natural hypothesis to examine is whether there is experimental evidence, for each of the combinations of fishing gear (5 levels) and habitat type (5 levels) for which data exists in the metadatabase, that fishing impact results in a change to the mean value of the response variable $Y$; e.g. do we see a significant initial decline in mean taxon abundance? Secondly, the consistency of such a decline, if it exists, needs to be examined across the combinations of gear and habitat. Thirdly, we are interested in testing for evidence of recovery of response over subsequent time periods. All 3 sets of hypotheses can be looked at by ANOVA tests, combined with CIs for the response means. In particular, if the mean (transformed) percentage change $(Y)$ has a $95 \%$ CI which does not overlap the value zero (based on a pooled variance estimate from the separate ANOVAs for each gear by habitat combination), this is formally equivalent to a $5 \%$ level test, rejecting the hypothesis of 'no change in mean taxon abundance from control conditions'. Much of the important interpretation in this paper will therefore be extracted from the Figs. $2 \& 3$ of means plots under different scenarios.

However, even the relatively coarse discrimination of 4 time periods since impact, with 5 fishing gears and 5 habitats, gives an impossible design, as stated earlier, due to the fact that some fishing gears are not used in certain habitats (e.g. scallop dredges are never used in mud habitats) and longer-term recovery data are not available for some treatment/habitat combinations. So, initially, 2-way ANOVAs were undertaken on 13 treatment/habitat combinations ('flattened' into a single factor) against 2 time levels ( 0 to $7 \mathrm{~d}$ post-fishing and $>8 \mathrm{~d}$ post-fishing), so that all cells in the 2 -way layout contain some data. Then, for each habitat/treatment combination we undertook 1-way ANOVA to elucidate further any differences in the magnitude of change in the response with time (now up to 4 periods, where possible).

Recovery by regression analysis: To examine patterns of recovery following fishing disturbance, responses were considered for all taxa irrespective of whether the initial response was positive, negative or absent. (This has not always been the approach adopted elsewhere, but we wished to avoid the dangers of selection bias in tracking further time periods only for sets of 'Day 1' data points that show significant initial decline, since such selection makes it possible to construct evidence for recovery that is artefactual). The slope of the change in the response to the fishing treatment with time was derived from a simple linear regression model. In only 1 case-biogenic habitats under scallop-dredging $(\mathrm{ScD})$ - was there evidence of non-linearity, and even here the use of a splinesmoother, although giving a better fit to the data, did not make an appreciable difference to the predicted recovery times. For these simple linear models, we arbitrarily defined recovery to have effectively occurred when the predicted lower 95\% confidence limit of the regression of percentage difference on time (linearly regressing $\log (1+X / 101)$ on $\log (1+t)$ ) returned to a value of -0.22 or larger, namely a point equivalent to a $20 \%$ reduction or less in the pre-impact value (of abundance, species richness or whatever). 
This was designed to give a conservative (i.e. precautionary) estimate of recovery time: if insufficient data exists at the later times to reduce the uncertainty in the regression line to a point where the lower confidence bound does not exceed this threshold at all, then it is conservative to conclude that there is no clear evidence of recovery.

In contrast, a still simpler criterion in which recovery is asserted occurs when the regression line itself returns to $Y=-0.22$ (20\% reduction). However, such an approach is non-conservative and could be said to encourage poor design: with fewer points in the plot, the chance of observing such a 'recovery' is increased. As with any such power statements, the use of $Y=-0.22$ (20\% reduction) rather than $Y=-0.10$ (10\% reduction) or a less stringent criterion is naturally somewhat arbitrary, and knowledge of the likely consequences of a partial recovery may help to dictate an alternative threshold choice. A further consideration is the limited temporal nature of many of the experimental studies, which were often less than 18 mo in duration. In cases where no recovery was observed within the time-limits of the available studies, extrapolation of the slope of recovery (and CIs) beyond the last time at which samples were recorded should be treated with great caution as the shape of the functional response is unknown. Therefore, when recovery times were ascertained by extrapolation, they were labelled as such.

Analysing specific phyla and functional groups: These regression analyses were performed for all (12) gear $\times$ habitat combinations that contained sufficient data at times after the initial impact for the analysis to be meaningful. They were then repeated on a finer subdivision of the data into (up to) 6 phyletic groups (see Table 1) for each gear/habitat type. This resulted in 68 subdivisions of the initial 2000+ points, but again many of these groups were devoid of data at postimpact time points, making regression analysis impossible. As described later, in such cases, tests of equality of initial impact allowed some of these phyla to be analysed in common. In cases where regression fits were possible, a variation of analysis of covariance (testing equality of slopes and intercepts simultaneously) allowed further sets of phyla to be combined. The result was a detailed breakdown of 30 combinations of gear/habitat/phyletic group, for each of which there is an estimation of the initial fishing impact and, in 18 cases, a regression line attempting to predict recovery times.

An alternative treatment of the same data then took only a subset of the gear/habitat combinations, those involving subtidal gear types only (scallop-dredging, $\mathrm{ScD}$; otter-trawling, OT; beam-trawling, BT) and gravel, sand and mud/muddy sand habitats (the latter 2 combined), and undertook the considerable task of identi- fying broad functional type for as many of the taxonomically-based data values as possible. Functional type was ascertained from peer-reviewed literature and consultation of experts when literature did not deal with a particular taxon. Analysis by gear/habitat/ functional group was then carried out, for the 2 major functional groups of deposit- (DF) and suspensionfeeders $(\mathrm{SF})$, in particular examining the evidence for any differences in their initial response to particular gears in some habitats.

Cautionary notes: One obvious but rather important point to note is that the limited nature of the metadatabase does not allow multivariate analysis of changing community structure. This is inevitable: experiments are from different locations with monitoring of differing faunal sets, and a common species list, consistently identified at all studies, could certainly not be constructed! Instead, each taxon abundance is separately compared with its value under the matching control condition, and species identities are then ignored in the analysis of the resulting (transformed) percentagechange values $Y$. Changes in community composition which are not reflected in reduced (or increased) mean abundance on average, across taxa, will be difficult to discern, because such changes will increase the variance of $Y$ rather than alter its mean. In fact, if the 'presence/absence' type of community change is the major short-term consequence of fishing impact, balanced between losses of vulnerable species and gains of opportunists such that total species richness is unaltered, one would expect a larger variance in $Y$ postimpact than at a later stage of recovery. There is, however, little evidence for this, the dominant impact being one of decreased abundance of most species. Whilst not denying, therefore, the additional insight that multivariate analysis would always bring, we recognise that univariate monitoring of decrease and recovery is the only realistic possibility in this context, and that it is likely to prove effective.

More serious is the implicit assumption that each of the 1759 response data items can be analysed as if they were statistically independent of each other. On the face of it this seems unlikely. There are only 68 studies (of 101 separate manipulations) producing these 1759 values and a purist view would demand that no study contributed more than 1 point to each analysis, the presumption being that since different studies take place at different places, times and under different environmental conditions - even in cases where they address the same gear and habitat types - there will be greater variance between studies than between response values (different taxa) within a study, and the 'proper' level of residual variation to test against is that between studies. To take such a view, however, is tantamount to accepting that a meta-analysis in this context 
is simply unfeasible and should not be attempted (until there are perhaps 30 or 40 independent studies for each of the 5 gear $\times 5$ habitat combinations, all of which have comparable - or at least measured - precision in relation to each other!). For example, the interpolation of 'study' as a random factor in the ANOVA analyses, crossed with gear, habitat and times, and in which the responses of individual taxa are nested, turns what are already extremely unbalanced designs into totally unworkable ones. So, we have taken a more pragmatic view of the issue: environmental practitioners can still gain insight by distilling experience from a wide range of studies, which cannot be put together into a balanced 'super-experiment'. There can be no watertight statistical analysis of this data, so we have chosen to carry out the simplest ANOVA tests and regression analyses, treating each response as independent, so that our 'naïve' analyses at least have the merit of being transparent to the reader. Of course, it is then imperative that due caution is exercised in interpreting any resulting statistical tests. There is therefore a general 'health warning' for this paper that it is more important to interpret the relative patterns of decline and recovery (which will not be unduly affected by any lack of independence of the data points in a regression, or in a means plot from an ANOVA) than it is to take seriously the precise significance levels that result.

The ANOVA results and plots that are given here do not, therefore, overstress the significance levels; furthermore, they report the number of independent studies alongside the number of data points used to calculate each mean. The effect of within-study correlations will be to make the 'true' degrees of freedom for the F-statistics somewhat lower than quoted, although all taxa within a study would have to be perfectly correlated to reduce the residual degrees of freedom to the magnitude of the number of studies. In fact, the sheer error variance of a single taxonresponse largely comes to our rescue in this context.
Some of the later plots demonstrate that individual data points (percentage change from control conditions) for a specific gear/habitat/time(/phylum) combination can vary from -100 to +100 (or more), and it is only through averaging over a large number of responses that any stability to the patterns emerges. In such circumstances, there is only a limited scope for correlations between individual values within a study, which would drastically reduce the effective degrees of freedom in the ANOVA or regression analyses, and widen the CIs in the means plots. We stress again, however, that an analysis that attempts to use just an average response for each study (across all taxa) in constructing ANOVA tests or regressions is not a solution to the potential problem of a 'study effect', since each study point would then be given equal weight. The reality is that the number of taxa making up the mean from each study in any one analysis is wildly unbalanced, so that one has simply exchanged over-optimism in residual degrees of freedom for a more serious problem. Taking the unit of observation as an individual taxon's response, and interpreting cautiously, is the better solution here.

\section{RESULTS}

\section{Grouped time periods}

\section{Gear/habitat combinations}

The majority of studies originated in either N Europe or NE America, while the main fishing gears studied were scallop dredges, otter trawls and beam trawls, perhaps reflecting a higher degree of concern regarding the effects of these methods of fishing. Softsediment communities were those most commonly studied and most occurred on sand habitats (Table 1). The distribution of fishing gears among habitats (Fig. 2) is instructive although perhaps not surprising. Inter-

Table 1. Distribution of studies $(\mathrm{n}=101)$ among main subgroups in meta-analysis database, and distribution of data points among phyla or summary-response variables and among fixed time ranges (days post-fishing disturbance) defined for initial stages of analysis. Treatments after Collie et al. (2000). Response variables other than individual taxa are number of individuals or total number of species reported per replicate

\begin{tabular}{|c|c|c|c|c|c|c|c|c|c|}
\hline Geographic division & $\mathrm{n}$ & Treatment & $\mathrm{n}$ & Habitat & $\mathrm{n}$ & $\begin{array}{l}\text { Phyla or } \\
\text { response variable }\end{array}$ & $\%$ & $\begin{array}{l}\text { Recovery-time } \\
\text { range (d) }\end{array}$ & $\%$ \\
\hline Northern Europe & 46 & Otter-trawling & 40 & Mud & 13 & Cnidaria \& Porifera & 6 & $0-1$ & 42 \\
\hline Southern Europe & 8 & Scallop-dredging & 24 & Muddy sand & 19 & Annelida & 30 & $2-7$ & 16 \\
\hline Eastern North America & 30 & Beam-trawling & 17 & Sand & 47 & Crustacea & 14 & $8-50$ & 13 \\
\hline Western North America & 1 & Intertidal dredging & 14 & Gravel & 11 & Mollusca & 22 & $>50$ & 29 \\
\hline Australia/New Zealand & 15 & Intertidal raking & 6 & Biogenic & 11 & Echinodermata & 9 & & \\
\hline \multirow[t]{2}{*}{ South Africa } & 1 & & & & & Others & 10 & & \\
\hline & & & & & & Species or individuals & 9 & & \\
\hline
\end{tabular}




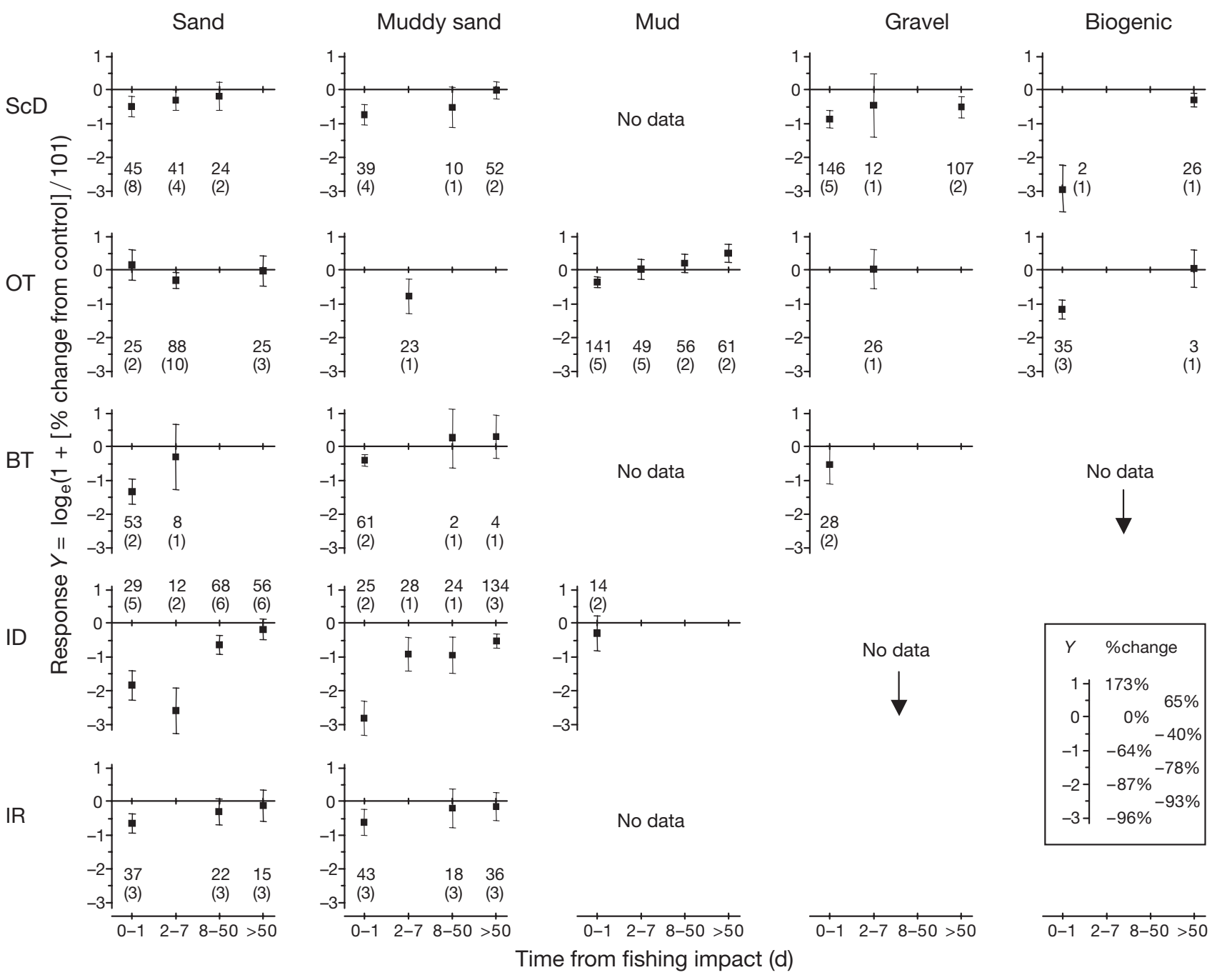

Fig. 2. Response $Y$ of benthic taxa to disturbance by different types of fishing gear in different habitat categories. $Y$ is logtransformed percentage change in abundance of each taxon in relation to control conditions $(Y=-4.6$ : complete removal, -2.2 : $90 \%$ reduction, $-0.7: 50 \%$ reduction, $-0.22: 20 \%$ reduction, $0:$ no change, $+0.22: 25 \%$ increase, $+0.7: 100 \%$ increase). The response is shown for 4 time categories $(0-1,2-7,8-50$ and $>50 \mathrm{~d})$; note that the final time bin varies between Days 50 and 1460 after a disturbance event. Data are means \pm 2 SE (from pooled SD for each plot); hence, there is no significant difference from a zero-response (no impact of trawling) if the error bar intersects the $x$-axis. For certain combinations of fishing gear and habitat there were either insufficient or no data. Numbers at the bottom or top of each graph: numbers of data points for that time interval and (parentheses) number of different studies contributing data points. ScD: scallop-dredging; OT: otter-trawling; BT: beamtrawling; ID: intertidal dredging; IR: intertidal raking

tidal raking and dredging (IR and ID, respectively) do not occur in either biogenic or gravel habitats and BT does not occur in biogenic habitats or mud. In addition, neither IR nor ScD occurs in mud habitats. The absence of the use of certain fishing gears in particular habitats reflects either their inability to be used effectively in these situations (a beam trawl would sink into a mud substratum), or the lack of appropriate target species (e.g. the scallop species considered herein do not occur on mud substrata). In contrast, some fishing activities such as OT and ScD are used across a wide range of habitats.
Two-way analysis

An initial 2-way ANOVA on the 11 fishing treatment/habitat combinations and post-fishing time ( 2 time levels: 0 to 7 and $>8 \mathrm{~d}$ ) indicated that the effect of fishing differed strongly among fishing treatment/ habitat combinations (ANOVA, $F=10.8$ ). Overall, the average effect of fishing ranged from a $72 \%$ reduction of the response variables (e.g. abundance of a taxon or total number of species within a sample) for ID in sand to no effective change in the response variable for OT in mud. There was a strong recovery of the 
Table 2. One-way ANOVA of taxon response $Y$ (transformed percentage change from control) to disturbance by different types of fishing gear in different habitats over time. Time was categorised into 4 groups: $0-1,2-7,8-50,>50 \mathrm{~d}$ after initial disturbance. For numbers of studies in each time group see Fig. 2. Of the 101 necessary studies, 68 provided specific taxon data that could be analysed in this way; the reminder provided only summary statistics (Fig. 3), or purely physical data, or lacked the controls to allow change calculations. nc: not able to compute temporal differences (i.e. only 1 time category in database); nd: no data found

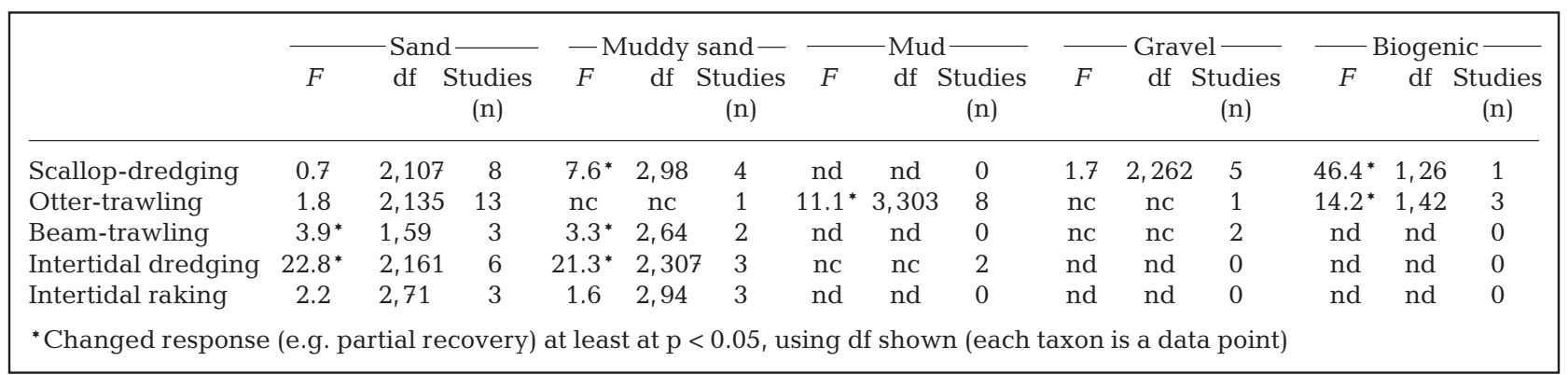

response variables with time (ANOVA, $F=107.2$ ), such that the average impact in the first 0 to $7 \mathrm{~d}$ post-fishing was a $58 \%$ reduction in the response variables, which in the $>8 \mathrm{~d}$ post-fishing category became only a $16 \%$ reduction compared with the control condition.

The above average values (the 'main effects') must be treated with caution as there was a large interaction between the fishing treatment/habitat combinations and time (ANOVA, $F=63.0$ ), which indicates that the recovery (reduction of the effect of fishing impact with time) differs across the fishing treatment/habitat combinations. The source of this interaction becomes clearer when the time categories are expanded to 4 levels: $0-1,2-7,8-50$ and $>50 \mathrm{~d}$ post fishing (Fig. 2, Table 2). This enables a simultaneous comparison of the instantaneous effect of a particular fishing gear in a particular habitat on the response variables and the change in the response to the initial disturbance for 4 consecutive time categories. The response of the taxon variable changed with time for only 8 of the fishing gear/habitat combinations (Fig. 2, Table 2).

\section{Results for each habitat type}

In sand habitats, the initial response was most severe with the application of ID, for which recovery had not occurred by the final time period. Beam trawling also had a relatively severe initial impact; however recovery appeared to occur rapidly, although it should be noted that there were only 8 data points in Time Intervals 2, 3 and 4 compared with 53 data points for the initial impact of BT (Time Interval 1). This reflected the tendency of most studies to examine initial impacts only. Interestingly, while OT had no significant initial impact in sand habitats, there is marginal evidence for a small delayed effect in the second time-interval postfishing disturbance; the same trend of delayed decline is also suggested in sand habitats for the severely impacted ID scenario.

In muddy sand habitats, the patterns of differences between fishing treatment and times are remarkably similar to those in sand. Given that these data are, in general, from different studies for the 2 habitats, this provides some reassurance about the generality and robustness of this meta-analysis approach. ID again had the most severe initial impact, the effect of which remained significantly different from a zero response condition across all post-fishing time periods. All the other fishing gears recorded had significant earlystage impacts on the response variables for muddy sand habitats (Fig. 2).

In mud communities, there were only data for OT and ID and most of the data involved the former. OT produced a significant, negative, short-term effect, but interestingly there was also a longer-term positive effect on the response variables (Fig. 2). For gravel habitats, ScD had significant short- and long-term effects on the response variables. Only 2 fishing-gear types were represented in biogenic habitats. Both $\mathrm{ScD}$ and OT had the most severe initial impacts in this habitat compared with their deployment in other habitats and for ScD there was no evidence of recovery by the fourth time period (Fig. 2), which in this case contained the longest post-impact periods recorded in the data set $(1460 \mathrm{~d})$.

\section{Whole-community descriptors}

A smaller subset of the studies reported the responses of the 2 bulk community descriptors: total number of species and total number of individuals. There was a significant negative response for the total number of species for ID in muddy sand. Although the relative response of the latter decreased with time, it remained significantly lower than a zero response 
across all time intervals (Fig. 3). None of the other fishing treatment/habitat combinations resulted in a significant response to fishing disturbance, however these other combinations had relatively few data points.

\section{Recovery patterns from linear regression}

Having established those fishing treatment/habitat combinations for which there was a significant effect of time, we re-analysed these data with time reinstated as a continuous variable and the data broken down into the response of either all taxa pooled (Appendix 2, available at www.int-res.com/articles/suppl/m311p001_ app.pdf) or different phyla (Appendix 3, available at www.int-res.com/articles/suppl/m311p001_app.pdf), fitting a simple linear regression whenever there were sufficient data from the later time periods. Although spline-smoothing functions were also fitted to the data, in all cases a linear regression gave a realistic, workable model for the data. The $95 \%$ confidence limits were plotted for these models and the point at which the lower confidence limit intersected the -20 and $-10 \%$ response horizons was chosen as indicative of the time at which recovery had occurred. The choice of response recovery horizon is illustrative only, and might vary according to different management objectives.

\section{Recovery for individual phyla}

The approach is exemplified in Fig. 4, for 2 contrasting cases. There was a significant linear regression with time for the data on the response of annelids to the effects of ID in both sand and muddy sand habitats (Fig. 4). Annelids were (conservatively) predicted to have recovered from the effects of ID by $98 \mathrm{~d}$ postfishing in sand habitats, but only by $1210 \mathrm{~d}$ post-fishing in muddy sand habitats (Fig. 4 ; note the different $x$ axis scales). However, the extrapolated date of recovery for the latter is well beyond the last observation time period and hence should be treated with caution as the shape of the relationship may not be linear beyond the last data point.

We examined such regression fits of all taxa pooled in 17 different fishing gear/habitat combinations (Appendix 2) which expanded further to 68 fishing gear/ habitat/phylum combinations, with the response of specific phyla (Appendix 3). The latter then reduced to 30 combinations after pooling those phyla for which the regression lines of their response were not significantly different (Appendix 3). Of these 30 combinations, 19 indicated a significant initial response to fishing disturbance which ranged from $-98 \%$ for Cnidaria and Porifera in response to $\mathrm{ScD}$, to $-24 \%$ for Annelida in response to OT in mud habitats (Appendix 3). The mean time to recovery to a $-20 \%$ recovery horizon occurred at $757 \mathrm{~d}$ for Cnidaria and Porifera in response to $\mathrm{ScD}$ in biogenic habitats (in this case the phyla in question are the main component of the biogenic habitat) (Appendix 3). Another set for which fairly long-term data are available is for ID in muddy sand. Although the extrapolated recovery period for Annelida, Crustacea and Mollusca was $870 \mathrm{~d}$, this result should be treated with care given that the longest reported study was sampled for only $540 \mathrm{~d}$, hence the shape of the recovery response beyond $540 \mathrm{~d}$ is uncertain.

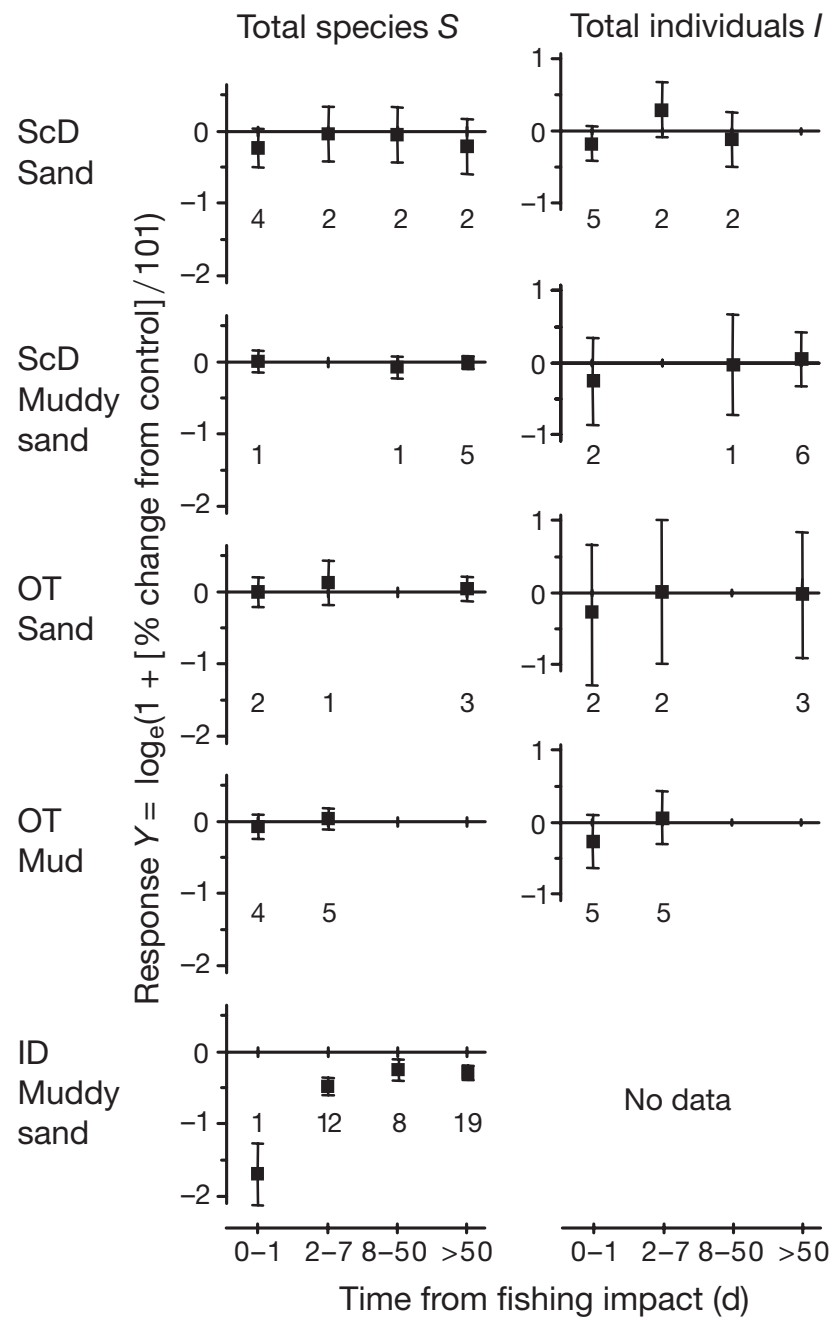

Fig. 3. Response of total number of species $(S)$ and total number of individuals $(I)$ to different types of fishing disturbance (abbreviations as in Fig. 2) in different habitat categories after an initial disturbance event, recorded over 4 time intervals, as in Fig. 2. Intersection of $95 \%$ confidence intervals with the zero-response line indicates no impact of trawling. ANOVAs for equality of response across the 4 time groups are not significant, except for $S$ in ID muddy sand $\left(F_{3,36}=14.5\right)$. Numbers at bottom of plots: no. of points on which means are based 


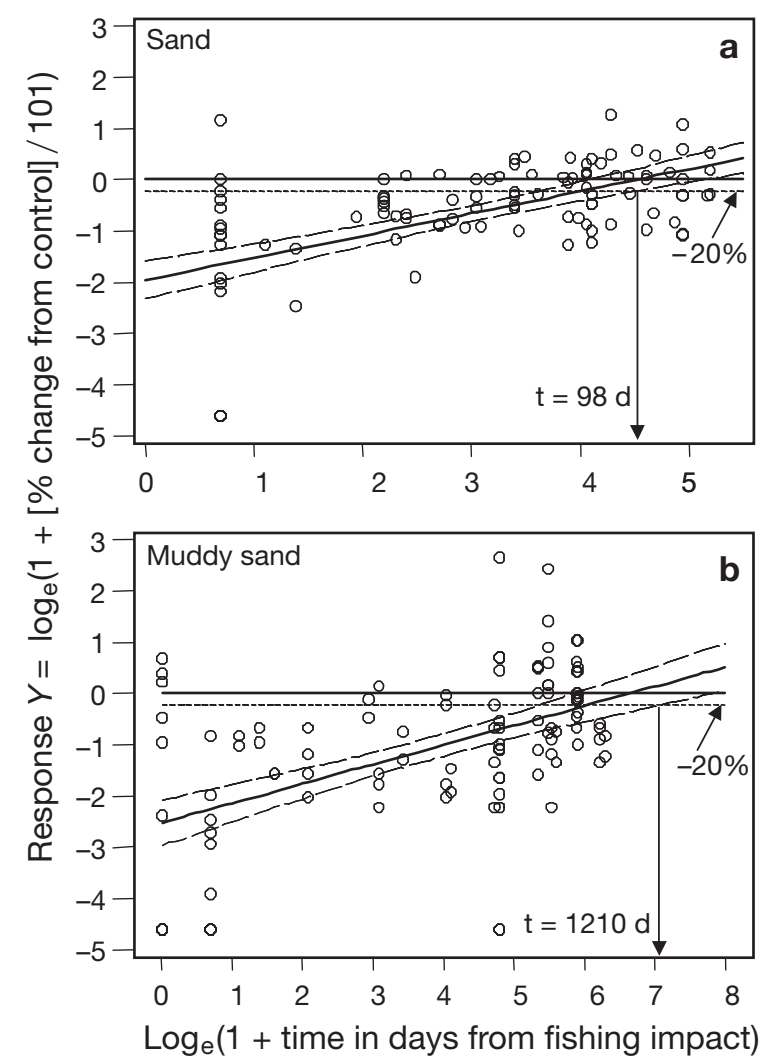

Fig. 4. Recovery in response $Y$ of Annelida to intertidal dredging in (a) sand and (b) muddy sand habitats. Vertical arrow: point at which $95 \%$ lower confidence limit for linear regression line intersects $-20 \%$ response horizon, which might be considered to constitute recovery. Note differing scales on time axes, and that in the case of intertidal dredging in muddy sand no study was carried out beyond Day $t=540$; hence, such extrapolations should be treated with caution. Regression statistics: (a) $\mathrm{R}=0.31(F=44)$, (b) $\mathrm{R}=0.27(F=38)$

In general, the main distinctions in Appendix 3 are between the different gear type/habitat combinations in Appendix 2 and Fig. 2, but there are also some differences of detail with regard to specific phyla. For example, the initial impact of BT in sand is much greater for crustaceans, echinoderms and molluscs than for annelids. The effect of IR in muddy sand is only evident for annelids and crustaceans, which show no evidence of recovery, in contrast to the molluscs, which appear unimpacted. Also in muddy sand, crustaceans appear more strongly impacted by OT than annelids and molluscs. In addition, there are big differences in phylum-level responses to $\mathrm{ScD}$ in gravel, ranging from an initial decline of $-71 \%$ in crustaceans, with no recovery at all, to no effect on annelids (close to a significant positive effect in fact). Other phyla are intermediate, with a more modest decline and only borderline evidence for recovery.
Recovery by functional group

When response variables were classified according to functional group, consistent trends were apparent for deposit- and suspension-feeding fauna in the short-term response to fishing disturbance. For both groups, $\mathrm{ScD}$ in general had the most negative effect in terms of overall mean response across gravel, sand and mud habitats, while OT had a uniformly less negative effect on both groups. OT had the greatest impact on SFs in mud habitats and this could reflect the great depth to which otter doors penetrate this soft sediment habitat. Interestingly, the response of both functional groups to BT was highly variable among habitats, with the most negative effect on DFs in gravel habitats, while SFs were most negatively affected in sand habitats (Fig. 5).

\section{DISCUSSION}

\section{Ranking of impact severity}

The recent increase in the available pool of data from studies that have examined the effects of fishing on the seabed has enabled us to undertake more formal structured tests for the effects of different fishing gears among habitat types. In contrast, Collie et al. (2000), were unable to examine the significance of interaction terms. For example, while Collie et al. (2000) were able to conclude that in general the effects of fishing activities in sand habitats lasted for only $100 \mathrm{~d}$, it was not possible to ascertain how this response varied among different fishing gears. However, in the present study, it is clear that the magnitude of both the initial and long-term impacts of different fishing gear types varies significantly among habitats (Fig. 2). As a result we were able to rank quantitatively those fishing gears that have the greatest initial and long-term impact in different habitats (Appendix 2). Previous reviews have alluded to such a ranking by relying on interpretation of the available literature but without a quantitative basis to support their conclusions (e.g. NRC 2002). It is therefore encouraging that many of these conclusions have been upheld by the present study, with certain exceptions. One of the critiques of experimental manipulations of fishing disturbance is that they do not adequately reproduce the activities of real fleets of fishing vessels, yet the advent of vessel monitoring systems indicates that the frequency of the impacts used in most experiments is representative of real systems in which fishing frequency is often less than once per annum, while hotspots of intensive fishing are relatively rare (Dinmore et al. 2003). 


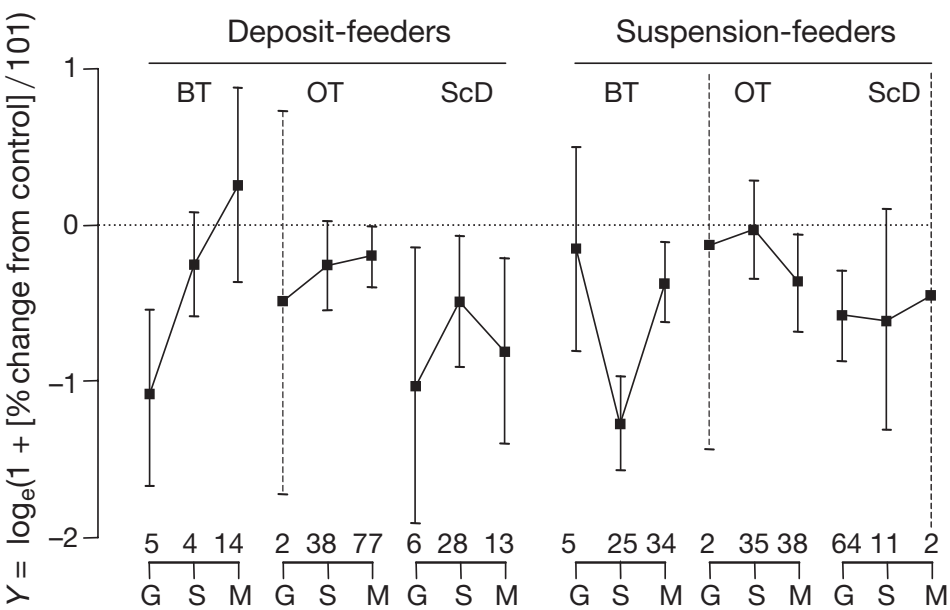

Fig. 5. Mean initial response (up to $7 \mathrm{~d}$ after impact), with $95 \% \mathrm{CI}$, of deposit- and suspension-feeding fauna to (BT) beam-trawling, (OT) otter-trawling and $(\mathrm{ScD})$ scallop-dredging in $(\mathrm{G})$ gravel, $(\mathrm{S})$ sand and (M) muddy sand/mud habitats combined. Dashed lines: CI where only 2 points available for mean calculation, and hence some intervals extend outside plotted range). Values above $x$-axis: number of data points in each mean calculation. Adequate test for a significant initial impact: whether $95 \%$ confidence interval crosses zero-response line

\section{Functional group analysis}

The analysis of the response of different functional groups of biota to trawl disturbance re-emphasises the ranking of the impacts of different fishing gears. Of the 3 subtidal gears considered in Fig. 5, the $6 \mathrm{ScD}$ combinations generally produced the largest negative mean responses (although 2 of the beam-trawl combinations are comparably low), while OT tends to have the least negative impact. In contrast, the response of these groups to beam-trawl disturbance is highly variable among gravel, sand and mud habitats, highlighting the importance of considering the interaction between some fishing gears and the habitat in which they are used.

\section{Intertidal habitats}

Turning to the intertidal studies, both ID and IR activities caused some of the most severe initial and overall impacts on soft-sediment habitats (Table 2, Fig. 2). This is no doubt partly attributable to the accuracy with which these gears can be used in intertidal habitats, either when exposed at low water or when covered by shallow water at high tide. In addition, it might be thought that the higher sampling power for such studies, given the relative ease of collecting samples from within disturbed and adjacent control plots, might skew the outcome in favour of apparent observation of 'more significant' impacts. However, the above analysis was designed to counter this effect, with its emphasis on the actual size of changes, rather than their statistical significance, and the use of threshold values for lower $95 \%$ confidence limits in judging recovery times. The impact of ID was much more severe than that of IR, probably related to the degree of physical disturbance inflicted upon the substratum. In the case of IR, the sediment is left in situ even though the upper few centimetres may be disrupted by the passage of the gear. Conversely, ID involves the physical removal and resuspension of the substratum into the water column. The furrows that result from these activities may be tens of centimetres deep (Beukema 1995, Dernie et al. 2003, Hiddink 2003). Thus, for ID, there is a significant component of habitat recovery in addition to biological recovery, that is required before a site can be considered to approach the condition of nearby undisturbed control plots (Dernie et al. 2003).

For sand habitats that are dominated by physical processes, habitat restoration is relatively rapid (days to a few months), whereas in muddy sand habitats that are mediated by a combination of physical, chemical and biological processes, habitat restoration is much longer (months or $>1 \mathrm{yr}$, Dernie et al. 2003). It is therefore not surprising that the projected recovery time for annelids in sand habitats subjected to ID was up to $98 \mathrm{~d}$ and that for muddy sand habitats was up to $1210 \mathrm{~d}$ (Fig. 4), although the latter is probably an over-estimate (see 'Results'). In the former case, recolonisation is probably dominated by active and passive migration of adults into the disturbed areas (e.g. McLusky et al. 1983), whereas in the latter case recolonisation is likely to require (in part) recruitment of larvae, and is therefore a much longer process. The phylum Annelida is a good representative of the biota in intertidal soft-sediment habitats. This phylum is often numerically dominant either in the early stages of recolonisation when small spionid worms can become predominant, or in later stages when tubiculous forms, such as ampharetid worms, competitively exclude opportunistic species and further consolidate the sediment through the construction of mucus-lined tubes (Dernie et al. 2003).

The relationship of the response of molluscs to fishing disturbance was characterised by large interactions of this phylum with gear/habitat: for example, molluscs subjected to ID in sand recover in $109 \mathrm{~d}$ after an initial response to fishing disturbance of $-83 \%$, whereas for many other gear/habitat combinations recovery cannot be determined. It must be remembered that most of the data in the database is composed of abundance data that is probably most representative of polychaete biomass. However, while molluscs may 
be relatively low in overall abundance within an assemblage, they may be dominant in terms of biomass, although this will vary with life-history (Beukema 1995). Thus, there may be a greater range in recovery rates within the phylum Mollusca compared to Polychaeta. Full recovery in terms of biomass (as opposed to recovery towards pre-fishing abundance) of the mollusc component of assemblages can take much longer than that for smaller-bodied fauna such as annelids (Beukema 1995). Some mollusc species have specific habitat associations (e.g. the nest-building bivalve Limaria hians) and are unlikely to recruit in the absence of a suitable habitat. In the case of L. hians, which is associated with maerl beds, the recovery time-scale of its associated habitat would be in the order of decades or centuries, given the growth rate of its biogenic habitat (Hall-Spencer \& Moore 2000).

The time-scales reported to be necessary for the recovery of annelids in these habitats are encouragingly similar to those reported by Dernie et al. (2003), who undertook an experimental manipulation in a range of replicated soft-sediment intertidal habitats that was designed to mimic the effects of ID at an appropriate scale. These data were not available at the time of data collection for the current meta-analysis. They therefore make an interesting validation data set against which to test the general responses indicated by the meta-analysis for the appropriate gear/habitat combinations. Dernie et al. (2003) demonstrated that there is a strong relationship between the rate at which the physical structure of soft-sediment habitats are restored and the rate at which the biological components of the system recover through either passive and active migration or larval recruitment. In addition, they were able to rank the rate at which recovery occurred in different habitats, which was most rapid for clean sand habitats, intermediate for mud habitats and longest for muddy-sand habitats, in agreement with the results of the meta-analysis (note that Dernie et al. 2003 did not examine gravel or biogenic habitats). They proposed that this ranking was related to the relative importance of physical, chemical and biological factors that affect sediment stability. Muddy sand sediments are the most stable of these habitats because they are influenced by a combination of all 3 processes (Dernie et al. 2003).

\section{Subtidal habitats}

$\mathrm{BT}$ and $\mathrm{ScD}$ had significant negative short-term impacts in sand and muddy-sand habitats (Fig. 2, Table 2); however, the relative effect was lower, and subsequent recovery times shorter, than for ID. This may be partly due to the highly energetic nature of shallow, subtidal, soft-sediment habitats in which physical processes will have a significant habitat-structuring influence (e.g. wave action and bed scour). OT had a significant initial effect on muddy-sand and mud habitats, but on the latter these effects were short-lived with an apparent long-term, positive, post-trawl, disturbance response (there were no recovery data for muddy-sand). This positive response may represent an increase in the abundance of smaller-bodied fauna, but a possible overall decrease in biomass in response to trawling (Jennings et al. 2001b, Duplisea et al. 2002). Past fishing-impact studies rarely reported community responses to fishing disturbance in terms of biomass (compared to abundance), which may be a more important ecological indicator of community structure and recovery. Gravel habitats, which are relatively stable and tend to support communities with high levels of diversity and biomass, were negatively affected by $\mathrm{ScD}$ both in the short and long-term although the initial impact was less pronounced than for other lessstable habitats (Fig. 2). ScD in biogenic habitats gave the greatest initial response of all fishing gear/habitat combinations, and the negative effects were predicted to last from 972 to $1175 \mathrm{~d}$ post-fishing (Appendices 2 \& $3)$. The effect of OT in biogenic habitats was less severe than for $\mathrm{ScD}$, but there was insufficient data to deduce an accurate recovery time based on published experimental manipulations.

Due to the prolonged recovery times experienced in biogenic habitats, most researchers have examined the effects of fishing by using comparative studies that have capitalised on large-scale closures or gradients in fishing effort (Collie et al. 1997, 2000, Kaiser et al. 2000a, Jennings et al. 2001a,b, Duplisea et al. 2002). Such studies were excluded from the current analysis, which considers only the results generated by experimental manipulations for which the time since fishing disturbance is known. Nevertheless, these comparative studies suggest that recovery time is similar to that reported here for $\mathrm{ScD}$ in biogenic habitats.

The number of studies that reported summary community data (species richness or total number of individuals) were limited, and few reported significant responses to fishing disturbance (Fig. 3). However, many of the experimental studies undertaken to date have examined the response of species richness to fishing disturbance at an inappropriately small scale in a bid to maximise replication within a given sampling effort (many small samples versus fewer larger-sized samples, Kaiser 2003). Fishing disturbances are largescale in nature, and require sampling effort to appropriately match the scale of the impact; hence many previous studies may have failed to report effects due to an inappropriate scale of sampling for univariate community metrics (see also Hill 1999). 


\section{Suitability of controls and definition of recovery}

There has been some debate regarding the utility of experimental studies that have manipulated the effects of fishing on seabed communities. It has been reasonably argued that the areas in which the studies occur are themselves subject to fishing by commercial fleets and therefore give disproportionately small responses to fishing disturbance compared to the same disturbance inflicted upon a pristine habitat (the so called 'moving baseline effect' of Pauly 1995 and Jackson et al. 2001). However, it is worth noting that several of the studies reported herein were undertaken in areas that have been closed to fishing (e.g. Tuck et al. 1998, Bradshaw et al. 2000, Sanchez et al. 2000), or in areas that are known from fisheries-enforcement data to experience only limited or no fishing effort (Kaiser \& Spencer 1996, Kaiser et al. 1998) or are known to have remained unexploited for reasons such as seabed obstructions (Ball et al. 2000). In particular, those studies that have been undertaken in biogenic habitats are very likely to represent the true magnitude of the effects of fishing, as fishing by a commercial fleet would have removed the biogenic habitat and thereby eliminated the possibility of conducting experiments in such a habitat. Furthermore, it is possible to find areas of very low fishing activity within areas of intensive commercial activity as ascertained from the satellite-tracking devices now deployed on vessels $>24 \mathrm{~m}$ long in N European and NE American waters (Murawski et al. 2000, Dinmore et al. 2003). Presumably such behaviour arises from knowledge of consistent past catches and lack of seabed obstructions in particular areas which results in a propensity for fishers to adopt a risk-averse strategy when fishing under the constraints of ever increasing restrictions (Jennings \& Kaiser 1998, Holland \& Sutinen 2000, Kaiser 2005). Nonetheless, whatever one's view on the adequacy or inadequacy of control areas in most of the fishing-impact experiments covered by this metaanalysis, it must be agreed that the primary response to fishing impact demonstrated here is a decline in taxon abundance (often a very substantial one) compared to 'controls'. 'Better' temporal controls in this situation would only have served to widen this gap, and reinforce the conclusions of this study more forcefully.

Our results of the projected recovery rates of the biota in different habitats are broadly supported by the findings of comparative studies of large-scale areas of the seabed from which fishing gears were excluded. For example, the recovery time of biogenic fauna on Georges Bank was from 2 to $5 \mathrm{yr}$ post-closure of the scallop fishery, a similar time-scale to that reported for a scallop fishery closure in the Irish Sea (Collie et al. 1997, Bradshaw et al. 2000). Bradshaw et al. (2000) added weight to the findings of other experiments by subjecting the 'recovered' areas within the scallop fishery closure to renewed fishing activity which resulted in a community structure similar to that in adjacent areas open to fishing.

It is important to re-emphasise the definition of recovery as used in the context of the present study. We extracted all information available in the published literature, which was most often reported as differences in mean abundance between control and treatment conditions. In a smaller number of cases, authors reported data for mean biomass, particularly when dealing with biogenic fauna, which in many cases are taxa that form colonies in which it is not easy to differentiate individuals. While a measure of abundance may adequately describe comparisons of small-bodied fauna such as annelids, it may not adequately describe recovery for larger biota such as sponges and soft corals. For these, a consideration of body-size is paramount, as biota of large body-size are more vulnerable and have lower intrinsic rates of increase and hence a lower capacity to sustain elevated mortality. Indicators such as the slope of the body-size spectrum of the benthic assemblage may provide better indicators against which to measure the state of the entire assemblage in response to disturbance treatments (Duplisea \& Kerr 1995, Duplisea et al. 2002, Jennings et al. 2002).

The present study has provided key information for (1) the quantification of the direct effects of bottomfishing disturbance on benthic biota in terms of the instantaneous removal or mortality of species in the trawl path and (2) the subsequent recovery rate in terms of density. The former can be integrated into size-based modelling approaches that enable reduction in biomass and production to be estimated (Duplisea et al. 2002, Hiddink et al. 2006). Biomass and production are much more meaningful indicators of ecological 'state' than density alone (Beukema 1995). Future studies that quantify the direct effects of fishing activity should quantify changes in body-size of fauna in addition to changes in abundance, as such metrics will become more useful for the validation of emerging modelling approaches.

Acknowledgements. This research was funded in part by the EU project COST-IMPACT ('Costing the Impact of Demersal Fishing on Marine Ecosystem Processes and Biodiversity', project reference Q5RS-2001-00993) and is a contribution to the Plymouth Marine Laboratory's (PML) core strategic research programme element on Functional Biodiversity. K.R.C. acknowledges his position as an honorary fellow of the PML. The project has been carried out within the framework of the MARBEF (Marine Biodiversity and Ecosystem Functioning) Network of Excellence, which is funded in the Community's Sixth Framework Programme (contract no. GOCECT-2003-505446). We thank the anonymous referees for their diligence and perception, which has led to a significantly improved paper. 


\section{LITERATURE CITED}

Auster PJ (1998) A conceptual model of the impacts of fishing gear on the integrity of fish habitats. Conserv Biol 12: 1198-1203

Auster PJ, Langton RW (1999) The effects of fishing on fish habitat. In: Benaka L (ed) Fish habitat: essential fish habitat and restoration. Symposium 22. American Fisheries Society, Bethesda, MD, p 150-187

Ball BJ, Fox G, Munday BW (2000) Long- and short-term consequences of a Nephrops trawl fishery on the benthos and environment of the Irish Sea. ICES J Mar Sci 57: $1315-1320$

Beukema JJ (1995) Long-term effects of mechanical harvesting of lugworms Arenicola marina on the zoobenthic community of a tidal flat in the Wadden Sea. Neth J Sea Res 33:219-227

Bradshaw C, Veale LO, Hill AS, Brand AR (2000) The effects of scallop-dredging on gravelly seabed communities. In: Kaiser MJ, De Groot SJ (eds) Effects of fishing on non-target species and habitats: biological, conservation and socio-economic issues. Blackwell Science, Oxford, p 83-104

Collie JS, Escanero GA, Valentine PC (1997) Effects of bottom fishing on the benthic megafauna of Georges Bank. Mar Ecol Prog Ser 155:159-172

Collie JS, Hall SJ, Kaiser MJ, Poiner IR (2000) A quantitative analysis of fishing impacts on shelf-sea benthos. J Anim Ecol 69:785-799

Dayton PK, Thrush SF, Agardy MT, Hofman RJ (1995) Environmental effects of marine fishing. Aquat Conserv 5: 205-232

Dernie KM, Kaiser MJ, Warwick RM (2003) Recovery rates of benthic communities following physical disturbance. J Anim Ecol 72:1043-1056

Dinmore TA, Duplisea DE, Rackham BD, Maxwell DL, Jennings S (2003) Impact of a large-scale area closure on patterns of fishing disturbance and the consequences for benthic communities. ICES J Mar Sci 60:371-380

Duplisea D, Kerr S (1995) Application of a biomass size spectrum model to demersal fish data from the Scotian shelf. J Theor Biol 177:263-269

Duplisea DE, Jennings S, Warr KJ, Dinmore TA (2002) A sizebased model for predicting the impacts of bottom trawling on benthic community structure. Can J Fish Aquat Sci 59: $385-426$

Gates S (2002) Review of methodology of quantitative reviews using meta-analysis in ecology. J Anim Ecol 71:547-557

Gurevitch J, Hedges LV (1999) Statistical issues in ecological meta-analysis. Ecology 80:1142-1149

Hall-Spencer JM, Moore PG (2000) Impact of scallopdredging on maerl grounds. In: Kaiser MJ, De Groot SJ (eds) Effects of fishing on non-target species and habitats: biological, conservation and socio-economic issues. Blackwell Science, Oxford, p 105-118

Hiddink JG (2003) Effects of suction-dredging for cockles on non-target fauna in the Wadden Sea. J Sea Res 50: 315-323

Hiddink JG, Jennings S, Kaiser MJ, Queirós AM, Duplisea DE, Piet GJ (2006) Cumulative impacts of seabed trawl disturbance on benthic biomass, production and species richness in different habitats. Can J Fish Aquat Sci 63: 721-736

Hill JK (1999) Butterfly spatial distribution and habitat re- quirements in a tropical forest: impacts of selective logging. J Appl Ecol 36:564-572

Holland DS, Sutinen JG (2000) Location choice in New England trawl fisheries: old habits die hard. Land Econ 76 : 133-149

Holme NA, MacIntyre AD (1984) Methods for the study of marine benthos. Blackwell Scientific Publications, Oxford

Jackson JBC, Kirby MX, Berger WH, Bjorndal KA and 15 others (2001) Historical overfishing and the recent collapse of coastal ecosystems. Science 293:629-638

Jennings S, Kaiser M (1998) The effects of fishing on marine ecosystems. Adv Mar Biol 34:201-352

Jennings S, Dinmore TA, Duplisea DE, Warr KJ, Lancaster JE (2001a) Trawling disturbance can modify benthic production processes. J Anim Ecol 70:459-475

Jennings S, Pinnegar JK, Polunin NVC, Warr KJ (2001b) Impacts of trawling disturbance on the trophic structure of benthic invertebrate communities. Mar Ecol Prog Ser 213:127-142

Jennings S, Pinnegar JK, Polunin NVC, Warr KJ (2002) Linking size-based and trophic analyses of benthic community structure. Mar Ecol Prog Ser 226:77-85

Kaiser MJ (2003) Detecting the effects of fishing on seabed community diversity: the importance of scale and sample size. Conserv Biol 17:512-520

Kaiser MJ (2005) Are marine protected areas a red herring or fisheries panacea? Can J Fish Aquat Sci 62:1194-1199

Kaiser MJ, Spencer BE (1996) The effects of beam-trawl disturbance on infaunal communities in different habitats. J Anim Ecol 65:348-358

Kaiser MJ, Edwards D, Armstrong P, Radford K, Lough N, Flatt R, Jones H (1998) Changes in megafaunal benthic communities in different habitats after trawling disturbance. ICES J Mar Sci 55:353-361

Kaiser MJ, Ramsay K, Richardson CA, Spence FE, Brand AR (2000a) Chronic fishing disturbance has changed shelf sea benthic community structure. J Anim Ecol 69:494-503

Kaiser MJ, Spence FE, Hart PJB (2000b) Fishing gear restrictions and conservation of benthic habitat complexity. Conserv Biol 14:1512-1525

Kaiser MJ, Collie JS, Hall SJ, Jennings S, Poiner IR (2002) Modification of marine habitats by trawling activities: prognosis and solutions. Fish Fish 3:114-136

Murawski SA, Brown R, Lai HL, Rago PJ, Hendrickson L (2000) Large-scale closed areas as a fishery-management tool in temperate marine systems: the Georges Bank experiment. Bull Mar Sci 66:775-798

Murtaugh PA (2002) Journal quality, effect size, and publication bias in meta-analysis. Ecology 83:1162-1166

NRC (National Research Council) (2002) Effects of trawling and dredging on seafloor habitat. National Academy Press, Washington DC

Pauly D (1995) Anecdotes and the shifting baseline syndrome of fisheries. Trends Ecol Evol 10:430

Pitkitch EK, Santora C, Babcock EA, Bakun A and 13 others (2004) Ecosystem-based fishery management. Science 305:346-347

Sanchez P, Demestre M, Ramon M, Kaiser MJ (2000) The impact of otter-trawling on mud communities in the northwestern Mediterranean. ICES J Mar Sci 57:1352-1358

Tuck I, Hall S, Roberston M, Armstrong E, Basford D (1998) Effects of physical trawling disturbance in a previously unfished sheltered Scottish sea loch. Mar Ecol Prog Ser 162:227-242

Submitted: February 16, 2005; Accepted: September 26, 2005

Proofs received from author(s): March 17, 2006 